\title{
Valorización inmobiliaria regional y escenario post-COVID-19. El caso de la Quebrada de Humahuaca*
}

\author{
Recibido: 29 de agosto de 2020 - Aprobado: 13 de octubre de 2020 \\ https://doi.org/10.22395/seec.v23n55a7
}

\section{Sergio Braticevic ${ }^{* *}$}

\section{RESUMEN}

El objetivo del presente escrito es analizar el proceso de valorización inmobiliaria regional, donde se toma como caso testigo a la Quebrada de Humahuaca (Argentina). La hipótesis de trabajo se plantea a partir del redireccionamiento de excedentes de capital hacia la esfera inmobiliaria, con la resultante transformación en las condiciones de hábitat. En consecuencia, se realiza un estudio multiescalar donde se demuestra cómo el mercado inmobiliario se nutre con inversiones de refugio de valor, ante un contexto de alta inflación o de sobreabundancia de capital. Para el ejemplo estudiado, se presenta una serie de precios entre 2004 y 2018. Así, se concluye que el incremento de los valores de la tierra en el espacio objeto se origina en las dos razones mencionadas, a la que se le suma el crecimiento turístico desde su declaración como Patrimonio de la Humanidad (Unesco). Para finalizar, se indaga sobre los posibles escenarios post-COVID-19, en el marco de baja de los precios inmobiliarios y una fuerte depresión de la economía global; en especial para el área examinada, que presenta una enorme dependencia de la industria del turismo.

\section{PALABRAS CLAVE}

Valorización Inmobiliaria; Excedente de Capital; Inflación; Mercado de Vivienda, post-COVID-19.

\section{CLASIFICACIÓN JEL}

R1, R14, R21, R31, R52.

\section{CONTENIDO}

Introducción; 1. Mercado inmobiliario y renta del suelo. Panorama regional; 2. La renta del suelo y su relación con la acumulación por desposesión; 3. Mercado de vivienda regional. Análisis postCOVID-19; 4. El ejemplo argentino. Inflación y mercado inmobiliario; 5. Estudio de caso. La Quebrada de Humahuaca; 6. Hábitat y precios en la Quebrada; 7. Conclusiones; Bibliografía.

\footnotetext{
La finalidad del artículo es mostrar un fenómeno poco estudiado en la región norte argentina, por esa razón la agencia de investigación nacional (Conicet) promueve su desarrollo a través de la Unidad Ejecutora local, el CISOR. Asimismo, el autor cuenta con un cargo permanente como investigador desde 2016 - en la Provincia de Jujuy - donde se estableció proveniente de Buenos Aires. Esto, a propósito de engrosar la masa crítica local. Además, es parte del proyecto de investigación de la Universidad de Buenos Aires: "Aportes a los estudios de frontera a partir de la valorización inmobiliaria reciente. El caso de la Quebrada de Humahuaca", UBACyT182BA (2018-2020); donde además es profesor de la asignatura Geografía Industrial, del área de economía de la Licenciatura en Geografía. Por último, si bien este trabajo comenzó durante 2016, terminó de realizarse en el año 2019; con su posterior redacción para 2020. Se trata de una extensa labor de campo y biblioteca, que redundó en la confección de una serie de precios inédita y de gran valor para el espacio objeto.

*. Geógrafo y Doctor en Antropología, Universidad de Buenos Aires, Buenos Aires, Argentina. Investigador en la UE-CISOR, Conicet, Provincia de Jujuy, Argentina. Dirección: San Martín 1028, San Salvador de Jujuy. Correo electrónico: sergiobraticevic@gmail.com. Orcid: https://orcid.org/0000-0002-9595-0388
} 


\section{REAL ESTATE VALORIZATION AND POST-COVID-19 CONTEXT. A CASE STUDY OF QUEBRADA DE HUMAHUACA}

\section{ABSTRACT}

The principal aim of this article is to analyze the regional real estate valorization process, through an examination of Quebrada de Humahuaca (Argentina). The hypothesis that is based on the re-direction of surplus capital to the real estate market, and the consequent transformation of the local habitats. This work intervenes in the phenomenon in a multiscale manner, examining the nature of the real estate market in the region, which was used as a reserve for value in an inflationary context or in an over accumulation process. At the same time, different series are presented in order to show to increases in real estate values (in US dollars), between the years of 2004 and 2018. Likewise, the increasing of real estate prices is based on two mentioned reasons, also the recent development of tourism in the region since the World Heritage Site declared by Unesco. Finally, the author presents the potential post-COVID-19 panorama, in the decline scenery of real estate valuations and the strong depression of global economy.

\section{KEY WORDS}

Real Estate Valorization; Surplus Capital; Inflation; Housing Market; post-COVID-19.

\section{JEL CLASSIFICATION}

R1, R14, R21, R31, R52.

\section{CONTENT}

Introduction; 1. Real estate market and land rent. Regional context; 2. Land rent and its relation with accumulation by dispossession; 3. Regional housing market. Analysis post-COVID19; 4. Argentine example. Inflation and real estate market; 5 . Study case. The Quebrada de Humahuaca; 6 . Habitat and prices in the Quebrada; 7. Conclusions; Bibliography.

\section{VALORIZAÇÃO IMOBILIÁRIA REGIONAL E CONTEXTO POST-COVID-19. 0 CASO DA QUEBRADA DE HUMAHUACA RESUMO}

O objetivo deste artigo é fazer uma análise sobre o processo de valorização imobiliária regional, com o caso exemplo da Quebrada de Humahuaca (Argentina). A hipótese de trabalho propõe a nova localização dos excedentes de capital na esfera imobiliária, acompanhado de transformações das condições de habitat. Assim, o autor apresenta uma investigação multiescalar, destaca-se a condição oferecida pelo mercado imobiliário como reserva de valor em um contexto altamente inflacionário o de sobre abundância de capital. Para o exemplo examinado, expõe diferentes séries com o objetivo de demostrar os incrementos de valores imobiliários (em dólares) entre os anos de 2004 e 2018. Neste sentido, conclui-se que o aumento dos preços da terra na região objeto relaciona-se com os fatores mencionados e uma terceira razão, o crescimento turístico depois da declaração como Património Mundial (Unesco). Do mesmo modo, ousa-se interpelar sobre o panorama post-COVID19, no contexto de baixa dos preços imobiliários e uma notável depressão da economia global.

\section{PALAVRAS-CHAVE}

Valorização Imobiliária; Excedente de Capital; Inflação; Mercado de Vivenda; post-COVID-19.

\section{CLASSIFICAÇÃO JEL}

R1, R14, R21, R31, R52.

\section{CONTEÚDO}

Introdução; 1. Mercado imobiliário e renda da terra. Panorama regional; 2. A renda da terra e a sua relação com a acumulação por despossessão; 3. Mercado de vivenda regional. Análise post-COVID-19; 4 . O exemplo argentino. Inflação e mercado imobiliário; 5. Estúdio de caso. A Quebrada de Humahuaca; 6. Habitat e preços na Quebrada; 7. Conclusões; Bibliografia. 


\section{INTRODUCCIÓN}

En la primera parte, se presenta un marco general del proceso de valorización inmobiliaria desarrollado de manera reciente a escala regional, de manera específica para el Cono Sur, a partir de causas concurrentes que se pueden sintetizar en la orientación de excedentes hacia la producción de espacio y —en particular - al mercado inmobiliario. En relación al mencionado fenómeno, se realiza un breve análisis sobre la renta del suelo y su relación con la acumulación por desposesión (Harvey, 2004) a través del acaparamiento de tierras (Costantino, 2016).

Más adelante, se revisa el ejemplo argentino, a partir de sus particularidades macroeconómicas. Todo ello conforme con el crecimiento económico experimentado durante el período 2003-2015, en especial hasta 2011, cuando la economía comienza a entrar en una fase de meseta y escasez de divisas; el conocido stop and go y el posterior go and crush de la economía argentina (Schvarzer y Tavonanska, 2008). Con la aceleración de la inflación y las sucesivas devaluaciones del peso local se implementan controles de cambios, tipos de cambio segmentados y mecanismos para evitar la fuga de capitales. Asimismo, y como ha sido a lo largo del tiempo histórico, el mercado inmobiliario se ha presentado como el refugio de valor más seguro, además de nominar las propiedades — casi en su totalidad - en moneda extranjera (dólar). Esta situación, poco frecuente, se da solo en algunos otros países, como es el caso del vecino Uruguay.

Finalmente, de manera más extensa, se interpela el caso específico de la Quebrada de Humahuaca, situada en la provincia de Jujuy, en el sector noroeste de la República Argentina. De forma particular, se analizan cinco localidades, a saber: Purmamarca, Tilcara, Maimará, Huacalera y Humahuaca. La relevancia que posee el territorio objeto es sustantiva, ya que se trata de un espacio patrimonial reconocido mundialmente, a la vez que ha observado una explosión en materia de turismo durante los últimos quince años, como casi ningún otro sitio de la Argentina. En el mismo sentido, el incremento de los precios de la tierra constituye un caso paradigmático a nivel nacional, mientras que posee una elevada oferta para sus magnitudes espaciales. De igual manera, el fenómeno del crecimiento de los valores inmobiliarios en zonas patrimoniales de carácter urbano y de transición hacia lo rural es un proceso escasamente estudiado en la Argentina.

En efecto, dicho espacio ha recibido inversiones públicas en infraestructura; tales como caminos, tendido eléctrico, servicios de red; situación que supuso un notable impulso al crecimiento económico regional. Dicho proceso cimentó bases más sólidas para el proceso de valorización y expansión de la frontera inmobiliaria. Este último concepto puede definirse como fajas de espacio físico o tierras que pasan a ser 
ofertadas en el mercado inmobiliario (otrora fiscales); o bien, áreas que incrementan de manera ostensible su valor de mercado; o que debido a un cambio en el uso del suelo se valorizan de manera creciente (en general, del ámbito rural al urbano). El citado fenómeno se conoce como gentrificación rural relacionada con el desarrollo turístico (Gascón y Cañada, 2016). Todo ello repensado desde las alternativas y constricciones que plantea el escenario post-COVID-19, en el marco de baja de los precios inmobiliarios y una fuerte depresión de la economía global; en especial para el área examinada, que presenta una enorme dependencia de la industria del turismo.

Por último, respecto de la metodología empleada, para el relevamiento efectuado entre 2004 y 2018 se realizaron entrevistas con ocho agentes inmobiliarios de la zona: Tierras Norte, Roca, ExcoNort, Aguado, La Red, Agostini, Bellomo y Noroeste; además de los vendedores particulares. Por su parte, registraron todos los avisos clasificados del diario provincial El Tribuno. La muestra final implicó un total de 242 casos, cifra más que considerable para el área de estudio. Todos los precios se tomaron en pesos argentinos (ARS) y se transformaron a dólares (USD); así, se presentan los valores de las propiedades a precios constantes y corrientes a partir de la inflación de la divisa norteamericana, de acuerdo al lapso temporal estudiado.

\section{MERCADO INMOBILIARIO Y RENTA DEL SUELO. PANORAMA REGIONAL}

Un horizonte temporal se puede marcar a partir del año 2008, momento en el cual se desata la crisis financiera en Estados Unidos a raíz del quiebre del mercado de hipotecas subprime. Esta situación propició otras crisis económicas - y de forma más específica, inmobiliarias - en España, por ejemplo. Diferente comportamiento observa una economía como la Argentina, donde el mercado inmobiliario se nutre de inversiones financieras que tienen como destino reserva de valor ante un contexto casi habitual de alta inflación. Sin embargo, los mercados de vivienda observan una estrecha relación con la sobreabundancia de capital y, por consiguiente, con una distribución regresiva del ingreso. Si se sigue esta línea de reflexión, se considera que la expansión global de las actividades inmobiliarias se vincula con la distribución inequitativa de la riqueza como producto social, así como la producción desigual de territorio y los procesos de fragmentación socio-espacial.

Por su parte, la expansión del mercado inmobiliario en diversos sitios del globo se apoyó, en gran medida, sobre un proceso que brindó una solución a la crisis de sobreacumulación (que se había vuelto crónica desde mediados de los setenta, siguiendo la tesis de Brenner), la acumulación por desposesión (Harvey, 2004).

Ante este escenario, los excedentes de capital pudieron encontrar destinos rentables en el ámbito inmobiliario, al hacerse de activos liberados a bajo costo, 
o bien, desde la creación de nuevos espacios de acumulación a partir de la construcción de viviendas. Este proceso no ha sido autónomo, fue acompañado por la construcción de infraestructuras a gran escala por parte de los distintos Estados, hecho que hizo posible el ahorro de costos y tiempo, y así acelerar el denominado proceso de compresión espacio-temporal (Harvey, 1988).

Para colocar otro aspecto relevante sobre la cuestión analizada, es necesario tener en cuenta la regresiva distribución del ingreso, variable que se agudizó durante los últimos tiempos. Así los describen Piketty junto con un grupo de más de treinta autores (Piketty, 2014), en una investigación llevada a cabo entre 1998 y 2013 , alrededor del problema de la dinámica histórica de los ingresos y la riqueza. En el trabajo mencionado, no solo se analizan los casos de Europa y Estados Unidos, sino también de América Latina, Asia y Oceanía.

A su vez, los citados procesos observan también su relación con la producción diferencial de espacio. De manera más particular, estos territorios muestran — desde hace varias décadas - una creciente fragmentación socio-espacial que se vivifica en fenómenos de gentrificación urbana', como resultado — en parte — de la mencionada distribución regresiva del ingreso.

\section{LA RENTA DEL SUELO Y SU RELACIÓN CON LA ACUMULACIÓN POR DESPOSESIÓN}

Conforme lo expuesto hasta aquí, la hipótesis de trabajo se plantea a partir de diversos factores concurrentes que habrían posibilitado el redireccionamiento de una porción considerable del capital financiero hacia el mercado de tierras en ciertos puntos del globo. En esta línea, se plantea que excedentes sin destino rentable dentro de sus propias ramas de capital, podrían haber encontrado realización en áreas de creciente valorización inmobiliaria; bien por el estímulo del crédito hipotecario; bien gracias a la enajenación de tierras públicas o fiscales por parte de actores inmobiliarios (en connivencia con los agentes estatales a cargo de la cuestión).

Uno de los factores sería el acaparamiento de tierras (Costantino, 2016) y el acceso al crédito barato, situación que entronizó la burbuja inmobiliaria y, en consecuencia, la crisis del sector y luego el crack de la economía. Otra variable en juego estaría dada por la regresiva distribución del ingreso que — como muestra Piketty (2014) — adquiere un cariz dramático en la actualidad a lo largo y ancho del globo. Gran parte del excedente que se reinvierte en el mercado inmobiliario proviene de dicha situación. No obstante, la concentración y centralización del capital no es una cuestión novedosa, pero sí agudizada durante los últimos

Como se trata de un concepto estudiado en amplitud, se puede consultar sobre la extensa producción académica en Mendoza (2016). Allí se menciona parte de los trabajos más importantes al respecto. 
decenios. Una de las consecuencias del citado proceso - planteada como una segunda hipótesis - supone la creciente dificultad de mantener un pacto social coherente y legítimo con semejantes niveles de desigualdad económica. En materia de hábitat social ${ }^{2}$, se traduce en un acceso diferencial a la vivienda, con mayores riesgos al incrementarse el endeudamiento privado de las familias.

En este punto, es necesario marcar la importancia que supone el concepto de renta de la tierra. En consecuencia, las formas de renta se sintetizan en diferencial (I y II), de monopolio y absoluta. Las primeras dos, desarrolladas por Ricardo (2004) y poco después por Marx, remiten a las diferencias producto de la fertilidad, la localización y el capital invertido en el suelo. La fertilidad genera producciones distintas y la localización costos diferenciales de producción, mientras que una inversión adicional de capital puede originar una ganancia extraordinaria. Así, Parias Durán (2010) cita a Jaramillo:

La renta absoluta y la renta de monopolio, de escasez, tienen la misma naturaleza y su determinante es una competencia estructural por los bienes agrícolas, que hace incrementar los precios de mercado de estos productos sistemáticamente por encima de sus precios de producción. (p. 153)

Por ende, la definición del concepto de renta de la tierra podría dividirse en estos dos grupos. No obstante, cabe señalar otros aspectos que influyen en los tipos de renta, tales como la competencia por los usos del suelo en el ámbito urbano, periurbano y semirrural. Según Jaramillo (2003):

En el contexto de los terrenos de una ciudad observamos que ella constituye la magnitud mínima de las rentas de todos los lotes urbanos: esa será la renta de los terrenos marginales en la ciudad que no tienen ninguna otra ventaja, y sobre ella se estructuran las otras rentas. Para el conjunto de los terrenos de la ciudad opera entonces como una renta absoluta, y por ello la llamamos renta absoluta urbana. (p. 37)

En este contexto, incluso la tierra más desprovista de servicios y con peor localización soporta este tipo de renta en el espacio urbano, mientras que las tierras rurales — en general — observan un nivel menor de renta. Aquí entran en juego otros factores, tales como la traducción de las rentas en precios del suelo (debe sumarse el constructo sobre el terreno, la provisión de servicios y la localización relativa); situación que determina un nuevo precio y conforma lo que se denomina renta absoluta

\footnotetext{
2 Se entiende por producción social de hábitat a los procesos generadores de espacios habitables que, además de tener en cuenta la construcción de vivienda, abarcan a la producción de espacios comunes de manera colectiva, consensuada y sin fines de lucro. En este sentido, no se trata meramente de una producción física de espacio, sino que se trata de la construcción de nuevas subjetividades espaciales y patrones de identidad que tienden a una reproductividad que difiere con respecto a los marcos que impone el mercado inmobiliario tradicional. Para más detalle, consultar Ortiz Flores (2012).
} 
urbana. Este sería el caso de tierras que pasan de usos rurales a urbanos, producto de la creciente valorización de la tierra gracias al incremento del turismo (como la Quebrada de Humahuaca); en el marco de un proceso que podría catalogarse de gentrificación rural (Gascón y Cañada, 2016).

Asimismo, en el ámbito urbano se generan otros tipos de rentas, además de las ya señaladas. Estas son las rentas primarias y secundarias, a saber: las primarias se relacionan con la fase inicial de la producción de espacio urbano, de forma específica la construcción de inmuebles. Aquí se desarrolla la renta diferencial en sus dos versiones, donde inciden las condiciones geomorfológicas para construir, la localización relativa, los servicios disponibles y los medios de transporte; factores que determinan la fertilidad territorial del espacio en cuestión (De Mattos, 1997, p. 2). La otra renta primaria es la renta absoluta urbana, descrita más arriba.

En cuanto a las rentas secundarias del ámbito urbano, estas se corresponden con los destinos y las posibilidades de utilización del espacio construido: uso residencial, comercial o industrial. Aquí se desarrollan rentas diferenciales y de monopolio. Otra renta —no menos importante- es la renta de segregación. Esta renta se relaciona con el acceso monetario a ciertos constructos que cuentan con un precio muy elevado. Si bien no es intención entrar en debates de la disciplina económica, podría afirmarse que el precio de mercado se encuentra bastante escindido por encima del valor del bien (en horas trabajo). Este mecanismo de mercado opera como un freno en el acceso a la vivienda para grupos sociales de escasos recursos económicos, excluyéndolos de ciertas áreas de la ciudad reservadas para las clases sociales más altas (Jaramillo, 2003, p. 41).

\section{MERCADO DE VIVIENDA REGIONAL. ANÁLISIS POST-COVID-19}

A escala regional, se advierten continuos problemas en materia de vivienda a lo largo del tiempo, tanto en el ámbito urbano como rural; pese a los esfuerzos por parte de distintos estados en solucionar dicha problemática. Sumado a esto, la pandemia iniciada a finales de 2019, que paralizó parte de las economías nacionales durante 2020; implicó que una porción de las finanzas públicas se orientase hacia la mitigación de los efectos adversos de la COVID-19. Así, en general, se relegó a un segundo plano cualquier otra política dirigida al hábitat, con razones más que sensatas.

No obstante, por ejemplo, en Argentina, se relanzó el Procrear desde el Ministerio de Desarrollo Territorial y Hábitat; plan que consiste en otorgar créditos blandos y a baja tasa de interés con el objetivo de adquisición o construcción de primera vivienda familiar (MDTH, 2020). Otro caso es el de Uruguay, que ofrece distintas 
herramientas y soluciones desde el Ministerio de Vivienda, Ordenamiento Territorial y Medio Ambiente (MVOT, 2020). Similar situación se da en Chile, desde el Ministerio de Vivienda y Urbanismo (MINVU, 2020).

Según diversas notas periodísticas recientes, todos los mercados inmobiliarios nacionales han sufrido las consecuencias provocadas a raíz de la COVID-19. En particular, en el Cono Sur, foco de la pandemia global durante el segundo semestre de 2020.

Por ejemplo, en Chile, se toma como punto de partida el estallido social que comenzó en octubre de 2019. Una de las razones de la protesta fue el acceso a vivienda digna, aunque no el central. De todos modos, gran parte del mercado se concentra en el área metropolitana de Santiago, que alberga alrededor del 40 \% de la población nacional (INE, 2018). Por su parte, el sistema de cuarentenas segmentadas según comuna imposibilitó mudanzas y traslados dentro de este gran tejido urbano. Se calcula que, por todas estas razones, los precios cayeron más de un $10 \%$ interanual. Distinto es el caso de Uruguay, que cuenta con un sistema de salud consistente tras la gestión del gobierno progresista del Frente Amplio, heredado por la actual alianza gobiernista multicolor de centroderecha. A raíz de esto, se pudo mantener achatada la curva de contagios, que desde el comienzo registra apenas más de mil casos. No obstante, la variación interanual de los precios fue de un $10 \%$ a la baja. También, influyó sobre el mencionado descenso la devaluación ocurrida desde marzo de 2020 con el cambio de gestión, de alrededor de un 20 \% (Ferreyra, 2020).

En síntesis, se puede aseverar que los efectos de la pandemia sobre el mercado inmobiliario y de viviendas se traduce en valores a la baja. Más que probable, este escenario se mantendrá e incluso empeorará, ya que la caída del empleo, el ingreso real, el ahorro y la inversión redundarán en menor demanda de bienes inmuebles de manera privada; así como menor asistencia pública en créditos para acceso al hábitat. No existe mucha bibliografía al respecto, ya que nos encontramos en la punta del iceberg, sin saber de manera exacta que deparará la economía regional y mundial en los próximos años. Pero sí se puede afirmar que se trata de un colapso económico de magnitudes similares, o aún peores, que la crisis de 1929.

\section{EL EJEMPLO ARGENTINO. INFLACIÓN Y MERCADO INMOBILIARIO}

En este apartado, se propone realizar un análisis centrado sobre los procesos de valorización inmobiliaria de forma reciente, para tomar en cuenta sus causas, implicancias y alteraciones con relación a la COVID-19; y así identificar posibles contextos post-pandemia. En efecto, se plantea revisar la cuestión del hábitat social a través de la identificación de fenómenos que se desarrollan de forma más particular sobre 
el mercado inmobiliario y el acceso a la vivienda, de acuerdo a la experiencia de la pandemia y su posterior escenario.

De manera habitual, los ladrillos han sido la reserva de valor más segura en Argentina. Pese a algunos vaivenes en los precios, con algunas excepciones debido a elevadas tasas de interés durante ciclos de especulación financiera, la adquisición de inmuebles se presentó como la mejor opción de inversión y ahorro a largo plazo. La segunda opción, que se acentuó durante los ciclos de endeudamiento, fuga y alta inflación, fue el atesoramiento en moneda extranjera (dólares). Esta situación trajo aparejada bajos niveles de reinversión de capital como contracara de la falta de ahorro interno. El último ciclo de dólar barato y sin cambio desdoblado se desarrolló entre 2015 y 2019. No obstante, los bienes inmuebles continuaron como la mejor opción de inversión. En el gráfico 1 se muestra la serie desde 1981, final del primer de ciclo de especulación financiera en Argentina, atraviesa la década de 1990 con el segundo periodo de peso apreciado y dólar barato, que finaliza con el comienzo del tercer momento ya mencionado. ${ }^{3}$

Se puede observar, entonces, que durante los años ochenta la alta volatilidad de la moneda local intensificó el atesoramiento y el ahorro en dólares, proceso que finalizó con una hiperinflación de más del 5,400 \% en el bienio 1989-1990. Una vez resuelto este problema, la propiedad inmueble siempre superó la rentabilidad de cualquier otra posición, situación que se prolonga hasta la actualidad.

Gráfico 1. Comparación entre inversiones financieras e inmuebles (2016).

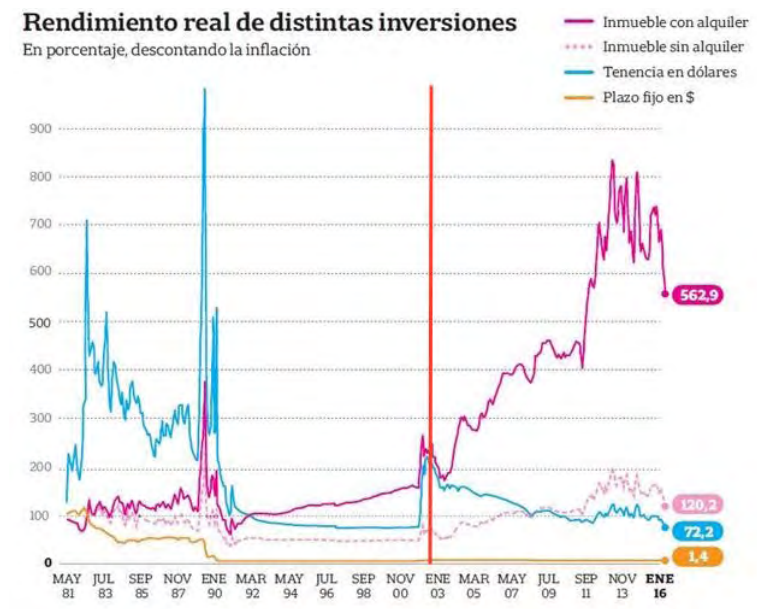

Fuente: Blanco (2016, p. 10), en base a BCRA y Diario La Nación.

Para un análisis más detallado sobre dicha situación, véase Barrera y Bona (2018). 
Ahora bien, el mercado inmobiliario local se mueve al compás de los vaivenes de la economía nacional, ya que la mayor parte de las adquisiciones se realizan por actores con sede en la República Argentina. De este modo, las variaciones sobre los precios, los costos de construcción, los valores de la tierra, la evolución del tipo de cambio y el crecimiento de la economía — en general — alteran los comportamientos sobre el mercado inmobiliario.

En efecto, el escenario post-COVID-19 plantea diversas constricciones a la hora de planificar y analizar el sector. Por lo pronto, para el mes de mayo de 2020 en la Provincia de Buenos Aires, que cuenta con más de 16 millones de habitantes y forma parte del Área Metropolitana de Buenos Aires, se firmó una sola escritura traslativa de dominio; contra 6.424 del mismo mes del año anterior (Fuchila, 2020).

Ante semejante contexto, no resta más que pensar en un mercado casi paralizado en su totalidad, hasta tanto no finalice la pandemia. Así, todas las previsiones presentan fuertes caídas en los PBI de la región, y Argentina no es la excepción. Como se analizó más arriba, ya se presentan descensos en los precios de las propiedades debido a esta parálisis. Dicha tendencia se profundizará de acuerdo al aumento de los casos de COVID-19, como ha venido sucediendo desde el pasado mes de julio (comienzo del invierno en el hemisferio sur).

Por su parte, se trata de un segmento de la economía que tiene diversos efectos multiplicadores sobre otras ramas. Por esa misma razón, se lanzó el Procrear, plan que consiste en brindar 300.000 soluciones habitacionales, entre créditos personales e hipotecarios; que comprenden el mejoramiento de la vivienda existente, la construcción en lote propio y nuevas unidades sobre desarrollos urbanísticos. En efecto, se trata de un proyecto que intentará reactivar el mercado de la vivienda desde el sector público, cuestión prioritaria para la economía nacional post-pandemia. Además, este tipo de programa está orientado al acceso a la primera vivienda y no a incrementar la especulación inmobiliaria, proceso analizado a partir de lo que se identificó como renta de segregación. Por último, hasta el momento no ha tenido un impacto muy considerable para la Provincia de Jujuy, ya que se han desarrollado otros planes; tales como el Federal de Vivienda y otras líneas provinciales que han suplido la demanda habitacional.

\section{ESTUDIO DE CASO. LA QUEBRADA DE HUMAHUACA}

Para el territorio objeto, la declaración como Patrimonio de la Humanidad por la Unesco, en el año $2003^{4}$, trastocó por completo la dinámica local, en especial lo

"El 2 de julio de 2003, la Unesco — en la asamblea XXVII del Centro del Patrimonio Mundial—incluyó a la Quebrada de Humahuaca en la lista del patrimonio mundial, en la categoría de Paisaje Cultural" (Tommei, 2010, p. 3). 
relacionado con los usos del suelo. Pasa de ser un lugar de cultivo (principalmente hortalizas) con riego, mano de obra intensiva y en pequeñas parcelas; a estructurarse como lugar orientado al turismo. Producto de dicha situación, se genera un mercado de tierras orientado a la inversión hotelera con desarrollos turísticos de media y alta gama. De manera compleja y contradictoria, lo indígena fue identificado como un obstáculo cultural para el nuevo proyecto de desarrollo; mientras que era parte fundamental de lo autóctono (Belli y Slavutsky, 2005).

Por ende, se puede señalar que el notable incremento de la población quebradeña, especialmente en las localidades de Humahuaca, Purmamarca y Tilcara, se debió al proceso mencionado más arriba. Así, la población de la Quebrada de Humahuaca creció desde el año 2000 a la actualidad casi un $40 \%$, pasando de alrededor de 30.000 habitantes a unos 42.000 para el año 2020; según estimaciones provinciales. A su vez, cuenta con una gran proporción de población indígena; más del $30 \%$ se autorreconoce como originaria (DiPEC, 2012). La principal actividad es el turismo y todos sus servicios relacionados; además de las tierras orientadas a cultivos, como se citó en el párrafo anterior. En el mapa 1, se identifican las regiones de la Provincia de Jujuy y su localización relativa respecto del resto de la Argentina y de los países limítrofes.

Mapa 1. Regiones de la Provincia de Jujuy y posición relativa en la República Argentina.

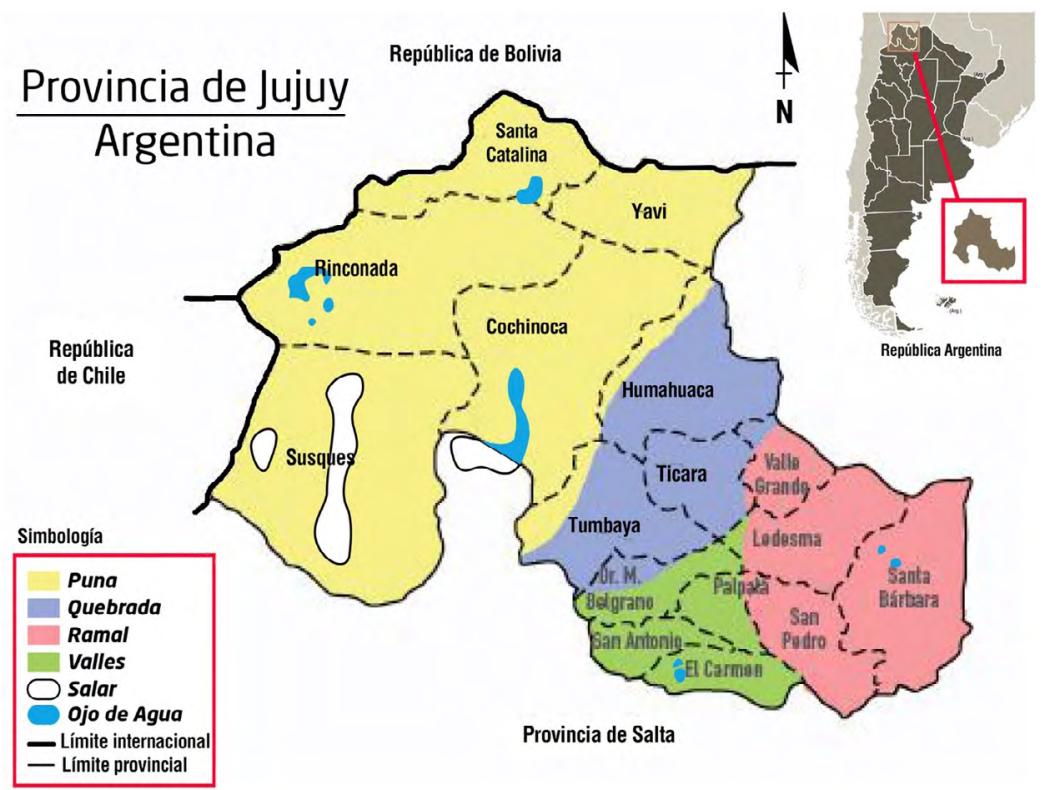

Fuente: elaboración propia en base a Secretaría de Turismo de Jujuy (2017). 
Tras más de quince años de la declaratoria, se puede aseverar que tanto el mercado de tierras (como la dinámica del hábitat social) se han transformado de manera notable. Los precios de la tierra entre 2004 y 2018 se han incrementado en alrededor de un $450 \%$, para el metro cuadrado de terreno limpio y con servicios (siempre con valores en dólares). Más adelante, se analizará en detalle esta situación. Sin embargo, no solo el acceso a la tierra se dificultó, los precios de los bienes en general se encarecieron, en especial los de primera necesidad en tiempos de temporada alta de turismo. Todo ello redundó en el incremento del costo de vida para la población local, que a medida que las tierras se vendieron se tuvo que ubicar en áreas más alejadas de los pequeños centros urbanos, con menor acceso a servicios; y en algunos casos con riesgo geomorfológico por desmoronamiento, como es el ejemplo de la localidad de Tilcara.

En el mapa 2 puede observarse el plan de sistematización de las microcuencas que rodean la localidad, a través de la mitigación hídrica de las quebradas que transportan flujos de derrubios, por remoción en masa, en épocas estivales (que es cuando más precipitaciones se producen). Vale la pena destacar que Tilcara se encuentra rodeada de material sedimentario en abanicos aluviales y que parte del ejido urbano se encuentra en zona de depósito. Esto implica un enorme riesgo durante cada verano para la ciudad, ya que las lluvias suelen ser torrenciales y nocturnas. Por su parte, el plan de mitigación citado aún no ha sido llevado a cabo.

Mapa 2. Riesgo socio-ambiental y plan de obras de mitigación hídrica. Tilcara (2016).

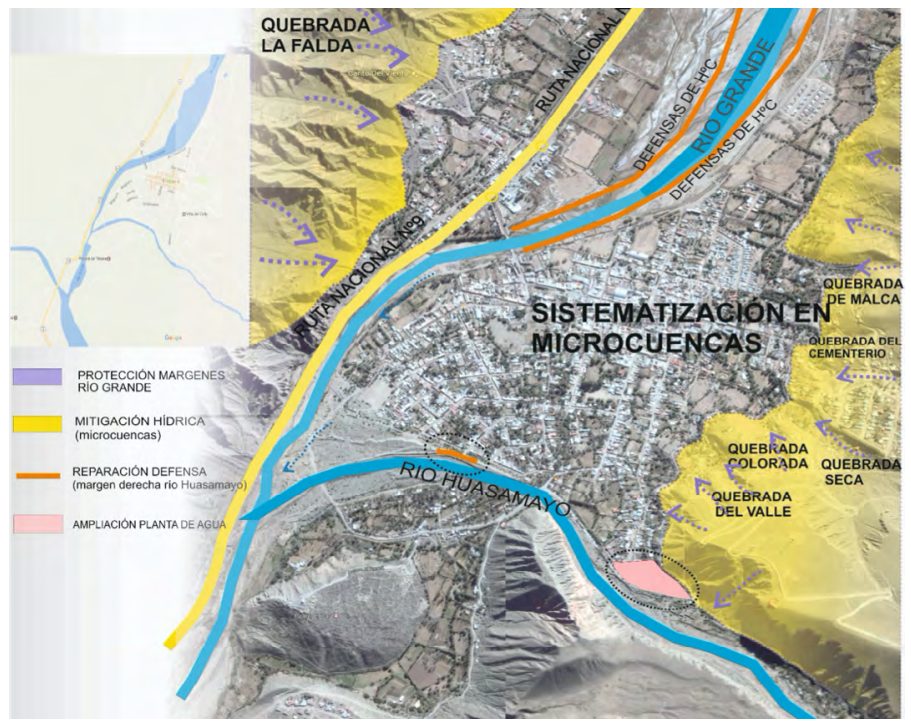

Fuente: Programa Hábitat. Ministerio del Interior, Obras Públicas y Vivienda de Nación (2016). 


\section{HÁBITAT Y PRECIOS EN LA QUEBRADA}

Como ya se mencionó, la alteración en los precios se inició con la declaración de patrimonio en 2003. Poco tiempo después, el crecimiento del turismo hacia esta zona del país se vio favorecido por la devaluación de 2002, tras diez años de paridad cambiaria con el dólar. Así, sucedieron dos situaciones; por un lado, el turismo interno optó por destinos locales, al encarecerse los viajes al extranjero; por el otro, los valores en relación al dólar observaron una tendencia a la baja, fenómeno que posibilitó la adquisición de tierras para quienes poseían moneda extranjera.

Como se mencionó más arriba, se exhiben cinco localidades de la Quebrada de Humahuaca: Purmamarca, Tilcara, Maimará, Huacalera y Humahuaca. La primera de ellas, se constituyó como la más cara y promocionada del área objeto. Así, Purmamarca ha sido la localidad donde mayor interacción observaron los procesos de patrimonialización y turistificación a lo largo de la Quebrada. No sólo en lo que refiere a lo arquitectónico, sino más bien respecto del desarrollo inmobiliario. Esto ha implicado que la población local se trasladara — en parte- hacia urbanizaciones polares o discontinuas con el ejido urbano principal, las comunidades indígenas de Chalala y Coquena (Tommei, 2017). Allí, los valores del metro cuadrado de terreno con servicios se incrementaron casi un 800 \%, en dólares, entre 2004 y 2018.

En una primera distinción, se puede afirmar que Tilcara y Maimará se orientan al público del mercado inmobiliario regional y local (Provincias de Jujuy, Salta y Tucumán), mientras que Purmamarca se encuentra más vinculada al mercado extra-local (con demanda desde las grandes urbes como Buenos Aires, Córdoba y Rosario). Si bien es casi imposible acceder al registro de propietarios, todos los agentes inmobiliarios entrevistados coinciden en afirmar este patrón, mientras que descartan la relevancia de las adquisiciones por parte de extranjeros, que han sido minoritarias.

En la tabla 1 pueden identificarse los precios en dólares a lo largo del periodo estudiado (entre 2004 y 2018). Como se observa, los incrementos porcentuales varían entre un $785 \%$ y un $245 \%$ según el caso. En este primer ejemplo, se muestran los valores en moneda extranjera a precios corrientes (sin contabilizar la inflación del dólar, ni la emisión monetaria por parte de la Federal Reserve Board - FED). 
Tabla 1. Precios por metro cuadrado de terreno limpio y con servicios. US $\$$ a valores corrientes. Quebrada de Humahuaca. Años 2004, 2011, 2016 y 2018.

\begin{tabular}{cccccc}
\hline Año & 2004 & 2011 & 2016 & 2018 & Variación Porcentual (\%) \\
\cline { 1 - 4 } Localidad & \multicolumn{5}{c}{ US\$ $/ m^{2}$} \\
Purmamarca & 20 & 74 & 142 & 157 & 785 \\
Tilcara & 22 & 48 & 96 & 108 & 491 \\
Humahuaca & 8 & 38 & 50 & 55 & 688 \\
Maimará & 22 & 35 & 42 & 54 & 245 \\
Huacalera & 16 & 25 & 32 & 48 & 300 \\
Quebrada & 20 & 45 & 84 & 88 & 440 \\
\hline
\end{tabular}

Fuente: elaboración propia con base en relevamientos con inmobiliarias de la zona, levantamiento en terreno y avisos clasificados del Diario El Tribuno.

En contraposición, si se resta la inflación según el índice de precios de los Estados Unidos, las variaciones de precios son menores, pero también contundentes. En la tabla 2 se observan los valores constantes —en dólares- desde 2004 a 2018. En todos los casos, se registraron precios en ascenso según la localidad.

Tabla 2. Precios por metro cuadrado de terreno limpio y con servicios. US\$ a valores constante. Quebrada de Humahuaca. Años 2004, 2011, 2016 y 2018.

\begin{tabular}{cccccc}
\hline Año & 2004 & 2011 & 2016 & 2018 & Variación Porcentual (\%) \\
\cline { 1 - 4 } Localidad & \multicolumn{5}{c}{ US\$ $/ m^{2}$} \\
\cline { 1 - 3 } Purmamarca & 20 & 62 & 88 & 119 & 595 \\
Tilcara & 22 & 40 & 75 & 82 & 373 \\
Humahuaca & 8 & 32 & 39 & 42 & 525 \\
Maimará & 22 & 30 & 33 & 41 & 186 \\
Huacalera & 16 & 14 & 25 & 36 & 225 \\
Quebrada & 20 & 38 & 66 & 67 & 335 \\
\hline
\end{tabular}

Fuente: elaboración propia con base en relevamientos con inmobiliarias de la zona, levantamiento en terreno y avisos clasificados del Diario El Tribuno. Deflactado a partir de index USCPI31011913, Bureau of Labor Statistics (FXTOP, 2020).

En relación al flujo turístico, la localidad de Tilcara se constituye como la más visitada en la Quebrada, junto con Purmamarca. Según datos de la Municipalidad, existen más de 120 establecimientos de alojamiento y unas 2.500 plazas disponibles; sector que representa más del 30 \% de la economía local (Municipalidad de Tilcara, 2018). A lo largo del periodo estudiado, se verificó un proceso continuo de gentrificación 
urbana y rural; propia de espacios otrora de cultivos, lo que más arriba se denominó renta absoluta urbana. De manera general, puede afirmarse que, al entrar en competencia con usos del suelo urbano en áreas turísticas, estos últimos priman sobre los rurales. Un ejemplo típico sería el de la hotelería. En el mapa 3 se distinguen los usos del suelo, la infraestructura urbana y los precios inmobiliarios para el año 2016. Allí, se encuentran identificados por zona al interior de la localidad analizada.

Mapa 3. Usos del suelo, infraestructura urbana y precios inmobiliarios (m²/US\$). Tilcara (2016).

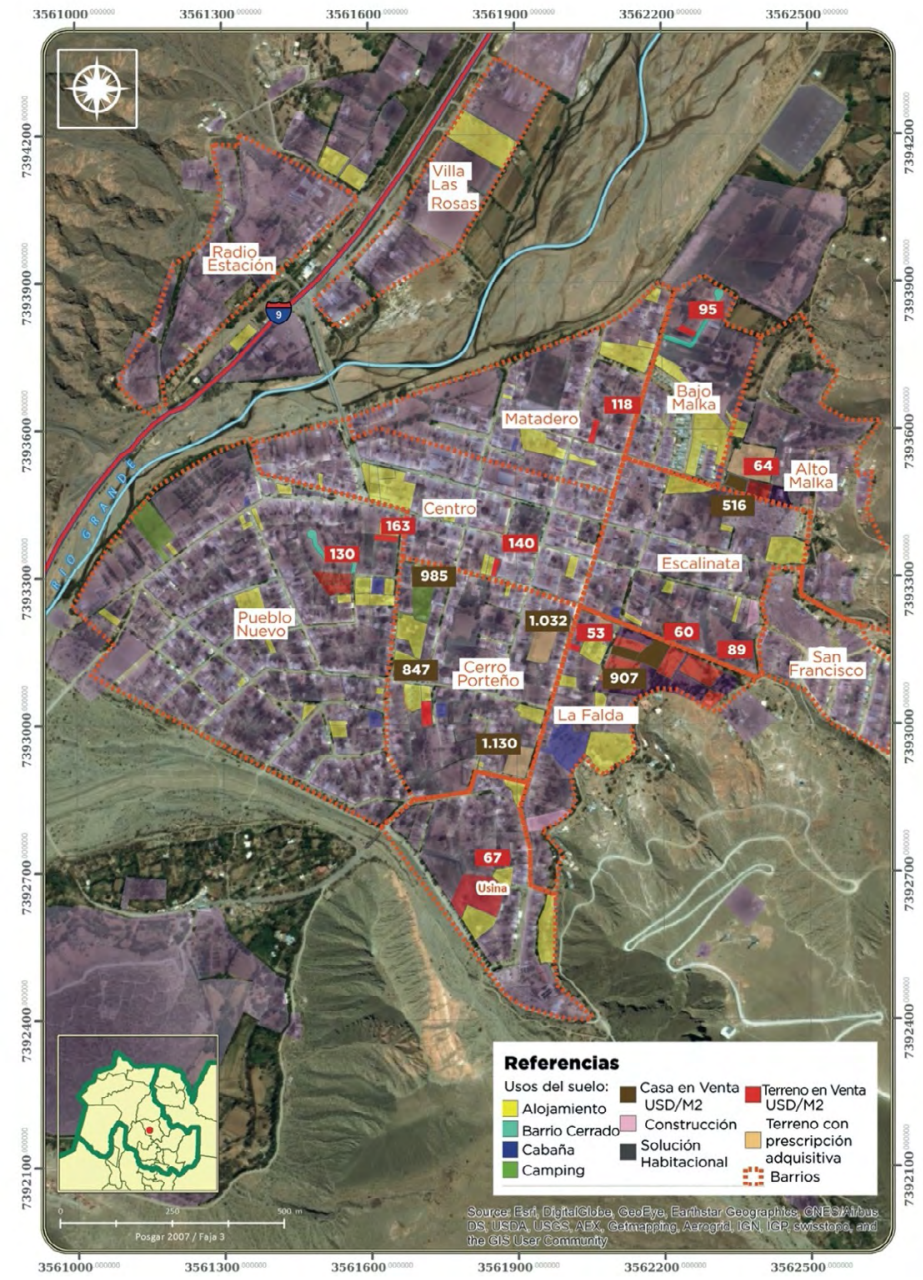

Fuente: elaboración con base en relevamiento personal (abril y octubre 2016) y Dirección Provincial de Inmuebles (2016), en conjunto con Minaglia y Bages (2020).

Sistema de coordenadas: POSGAR 2007, Faja 3.

Realizado con software libre: QGIS Las Palmas 2.18.9. 
En este contexto, la morfología urbana se compone de establecimientos relacionados, de manera directa o indirecta, con el desarrollo turístico comenzado a principios de los años 2000. En este sentido, predomina un paisaje boutique, que al distanciarse del centro pierde homogeneidad. Así, los barrios localizados sobre los faldeos de las montañas, con menor provisión de servicios y mayor riesgo ambiental, registran mayores niveles de segregación socio-espacial respecto del centro urbano, situación que se traduce en una producción diferencial de hábitat.

El citado proceso de gentrificación observó estas consecuencias, además de la suba general en los precios de los bienes de primera necesidad en épocas de temporada de turismo. Sumado a todo esto, durante los últimos años se anexaron pobladores provenientes de otras zonas de la Quebrada y de la Puna, gracias a un doble proceso: la falta de trabajo en sus lugares de origen, más las posibilidades de encontrar algún empleo en las localidades turísticas.

Para el caso de la localidad más próxima (Maimará) se trata de un poblado pequeño dedicado a la agricultura de carácter intensivo. Sin embargo, observa una constante presión inmobiliaria sobre sus tierras, ya que se erige como un espacio de proximidad en el corredor turístico entre Tilcara (distante a $8 \mathrm{~km}$ ) y Purmamarca (a unos $18 \mathrm{~km}$ ). Así, muchas parcelas de usos rurales pasaron ser hospedajes o cabañas de campo. En la actualidad, Maimará cuenta con más de 30 alojamientos; mientras que los precios se incrementaron, aunque en menor medida respecto de sus dos localidades aledañas.

De todos modos, se repite un mismo patrón espacial a lo largo de la Quebrada: una cantidad variada de loteos urbanos dirigidos al desarrollo inmobiliario y turístico. Por su parte, todavía se encuentra tierra disponible localizada en áreas periurbanas para el cultivo por riego.

De este modo, lugares tales como Humahuaca, Huacalera, Uquía y Villa El Perchel poseen rasgos distintivos en sus zonas periurbanas, donde se alternan grandes propiedades y pequeñas chacras de finqueros locales (con gran capacidad de ahorro sobre la base del trabajo familiar y un alto nivel de autoexplotación).

Para el caso de las dos primeras localidades citadas, se trata de espacios urbanos con mayor oferta de tierra; tanto urbanas, como rurales. Para el periodo estudiado, concentran más del $50 \%$ de los terrenos en venta (aproximadamente unos $142.000 \mathrm{~m}^{2}$ ). Son las ciudades más al norte de la Quebrada, registran más altura sobre el nivel del mar (encima de los 2.700 metros), menor provisión de servicios y se encuentran más alejadas del circuito turístico. De forma habitual, la última escala suele ser Tilcara, debido a que se trata de una distancia óptima desde Salta; lugar 
donde se encuentra gran parte de las agencias de turismo y el aeropuerto con mayor flujo de la región. Según datos oficiales, el Aeropuerto Internacional de Salta registró un total de 1.111.000 pasajeros durante 2018. Así, se ubicó en el sexto lugar a nivel nacional, por lo que supera a Tucumán (933.000) y a Jujuy (395.000) (EANA, 2018).

Es decir, gran parte del turismo dentro de la Provincia de Jujuy es coordinado desde la vecina Salta, próxima a unos $150 \mathrm{~km}$ de la Quebrada de Humahuaca. Vale la pena recordar la importancia de los visitantes nacionales y regionales en el espacio objeto. A su vez, este circuito se estructura con Purmamarca y Tilcara como vértices, en paquetes de no más de una semana y con bajos niveles de permanencia. Según la Jefatura de Gabinete de Tilcara, la estadía promedio en la localidad es de dos días (2018).

Ahora bien, la oferta de tierras en las localidades mas norteñas (Humahuaca y Huacalera) alterna terrenos rurales y urbanos de mayor tamaño en promedio. En muchos casos, son destinados a usos rurales, algo menos usual en las ciudades sureñas de la Quebrada (Tilcara y Purmamarca). Para el caso de las dos primeras, Humahuaca observó las subas más elevadas para el periodo estudiado, después de Purmamarca. Esto se debió a la oferta de parcelas de gran tamaño, hecho que produjo que el metro cuadrado registre el valor más bajo durante 2004 para todo el espacio objeto (apenas 8 US\$). A partir de este precio, trepó para el año 2018 hasta los 55 US\$ a precios corrientes (42 US\$ a precios constantes). Por su parte, Huacalera pasó de 16 a 48 US\$ y 36 US\$. No alcanzaron los valores de Purmamarca (157 y 119 US\$) ni de Tilcara (108 y 82 US\$); pero sí de Maimará (54 y 42 US\$).

En el mapa 4 se identifican los precios corrientes en dólares (por metro cuadrado) para toda la Quebrada de Humahuaca entre 2004 y 2018, con sus respectivas variaciones porcentuales. También se observa la posición relativa respecto de la República Argentina, los poblados actuales, los sitios residenciales y estratégicos de control durante el periodo prehispánico. Esto, a propósito del valor patrimonial de la zona en relación al incremento de los precios inmobiliarios. En este sentido, la existencia de dichos paisajes opera de manera indirecta en el aumento reciente de los valores de la tierra; además de tratarse de un espacio patrimonial reconocido internacionalmente, con la contradicción que conlleva armonizar su conservación con el avance de la frontera inmobiliaria. Por ejemplo, en muchas limpiezas de terreno (que cuentan con los correspondientes permisos) se encuentran vestigios arqueológicos sin seguir los protocolos necesarios. 
Mapa 4. Precios de la tierra por metro cuadrado en dólares. Quebrada de Humahuaca. Años 2004-2018.

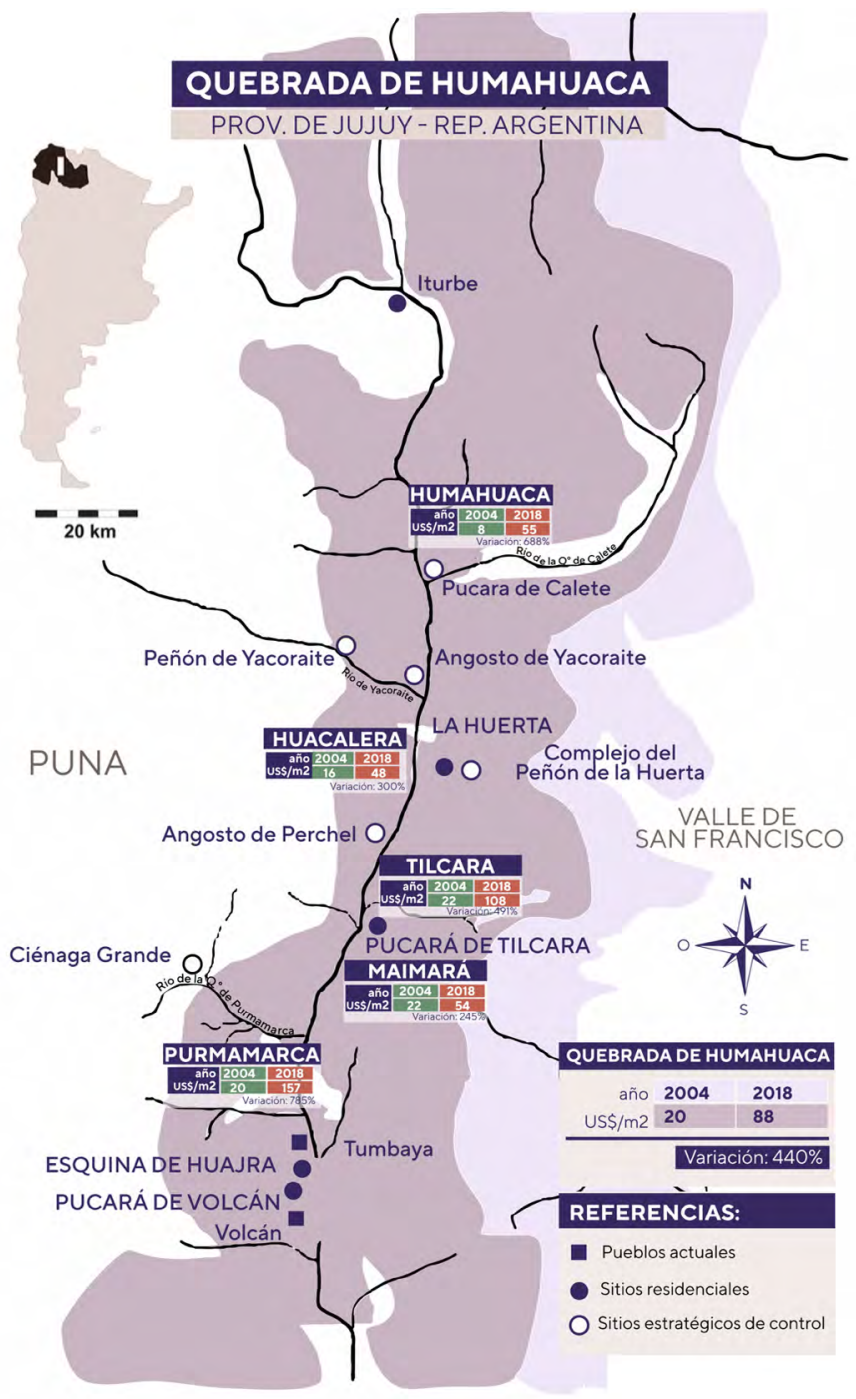

Fuente: Minaglia y Bages con base en Ochoa (2017).

En la tabla 3 se muestra la cantidad de tierra ofertada durante el periodo estudiado. Como se mencionó más arriba, Huacalera y Humahuaca concentran el $52 \%$ de la oferta, le sigue Purmamarca con el $11 \%$, Tilcara con el $8 \%$ y Maimará con el $6 \%$. Otras localidades tales como Villa El Perchel, Juella, Chucalezna y Uquía; poseen una disponibilidad rural y dispersa, aunque con el $24 \%$ del total en el lapso examinado. 
Valorización inmobiliaria regional y escenario post-COVID-19. El caso de la Quebrada de Humahuaca

Tabla 3. Oferta total en metros cuadrados. Quebrada de Humahuaca. Años 2004-2018.

\begin{tabular}{ccc}
\hline Localidad & $m^{2}$ & Porcentaje \\
\hline Huacalera & 93.224 & $34 \%$ \\
Humahuaca & 47.486 & $18 \%$ \\
Purmamarca & 28.524 & $11 \%$ \\
Tilcara & 21.105 & $8 \%$ \\
Maimará & 15.575 & $6 \%$ \\
Otras & 65.325 & $24 \%$ \\
Total & 271.239 & $100,00 \%$ \\
\hline
\end{tabular}

Fuente: elaboración propia con base en relevamientos con inmobiliarias de la zona, levantamiento en terreno y avisos clasificados del Diario El Tribuno.

Por último, todas las localidades han registrado una ralentización en el crecimiento de los precios en dólares desde el año 2016, a raíz de la saturación en inversión hotelera, la merma del turismo interno y, de manera reciente, la aparición de la pandemia global. Los datos que pudieron relevarse hasta el momento, muestran que los valores alcanzados durante 2016 (alrededor de 84 US\$) treparon hasta los 88 US\$ en 2018, mientras que para el año 2020 no llegan siquiera a los 90 US\$. Esto se debió a un doble proceso; por un lado, los precios habrían tocado un techo a raíz de la sobreinversión; por el otro, los efectos de la pandemia reflejan muy bajas perspectivas para el sector turístico en el corto plazo. Todo ello, en un escenario con suspensión de vuelos, cierre de comercio, merma del poder adquisitivo, entre otros factores.

Asimismo, Jujuy registró entre los meses de julio y septiembre de 2020 unos de los índices de contagio más altos del país; por lo que fue declarada por el Gobierno Nacional como zona roja a la hora de la reapertura de actividades, situación que en el mes de octubre se mantiene en varios departamentos de la provincia. En síntesis, se trata de una situación compleja para disponer la reapertura de actividades, en un área donde el turismo representa gran parte de la economía local. Por ejemplo, la Municipalidad de Tilcara calcula que entre un 70-80 \% de la actividad local se cimienta sobre dicha industria (Municipalidad del Tilcara, 2018).

\section{CONCLUSIONES}

A lo largo de este escrito, se intentaron explicar fenómenos tales como el redireccionamiento de capital excedente hacia la esfera inmobiliaria y la adquisición de propiedades como una opción de refugio de valor; y, en particular, examinar un proceso poco estudiado en zonas urbanizadas de manera reciente, en la región 
norte de la Argentina. Así, el desarrollo del turismo, con sus efectos positivos y negativos, reportó novedosas situaciones de diferenciación social, producción fragmentaria del espacio y de las condiciones disímiles de hábitat; entre las más destacadas. En efecto, circunstancias tales como la sobreabundancia de capital y la utilización del mercado inmobiliario como reserva de valor, hicieron factibles procesos de valorización de la tierra, relacionados de manera estrecha con la gentrificación urbana y rural; como se analizó en el presente artículo y se demostró a través del aumento de los precios inmobiliarios.

Sumado a todo esto, la aparición de la pandemia global durante el año 2020 trastocó gran parte de las prácticas económicas, sociales y culturales que se conocían hasta el momento. La industria del turismo no fue ajena a la situación mencionada, tampoco el mercado inmobiliario. La economía mundial sufre de forma casi inédita dicha crisis. Quizás, lo más cercano haya sido el crack de 1929. No obstante, las implicancias e interdependencias son bien diferentes. Para el caso estudiado, la dependencia del flujo turístico no visualiza una solución a corto plazo; mientras que el mercado de tierras local se encuentra paralizado. En síntesis, el contexto post-COVID-19 plantea con suma urgencia la importancia del rol estatal, como la diversificación en materia económica, a propósito de mitigar la profunda crisis que dejará como resultado la pandemia sobre territorios como el estudiado.

\section{BIBLIOGRAFÍA}

Barrera, M. A. y Bona, L. M. (2018). La fuga de capitales en la Argentina reciente (1976-2018). Revista de la Facultad de Ciencias Económicas, 26(2), 7-32. https://doi.org/10.18359/rfce.3059

Belli, E. y Slavutsky R. (2005). Discursos patrimonialistas. Consecuencias prácticas. En E. Belli y R. Slavutsky (eds.) Patrimonio en el Noroeste Argentino: otras historias (pp. 39-64). FFyL / UBA.

Blanco, J. (2016, 2 de agosto). Ni tasa ni dólar: sólo los ladrillos resistieron los cambios de modelo. Diario La Nación, p. 10.

Costantino, A. (2016). El capital extranjero y el acaparamiento de tierras: conflictos sociales y acumulación por desposesión en Argentina. Revista de Estudios Sociales, 55, 137-149. http://dx.doi.org/10.7440/res55.2016.09

De Mattos, C. (17-21 de marzo de 1997). Dinámica económica globalizada y transformación metropolitana: hacia un planeta de archipiélagos urbanos. VI Encuentro de Geógrafos de América Latina. EGAL.

Diario El Tribuno de Jujuy (2004-2018). Relevamiento histórico precios de la tierra en la Quebrada de Humahuaca. Biblioteca del Instituto Interdisciplinario - UBA.

Dirección Provincial de Estadística y Censos (2012). Anuario Estadístico. Gobierno de la Provincia de Jujuy. Consulta: 23 de agosto de 2018. http://www.dipec.jujuy.gov.ar/anuario2012.html 
Ferreyra, L. (2020, 4 de junio). Cómo afecta el Covid-19 al mercado inmobiliario regional. Diario Ámbito Financiero. https://www.ambito.com/negocios/uruguay/como-afecta-el-covid-19-almercado-inmobiliario-regional-n5107532

Fuchila, M. (2020, 20 de mayo). Parálisis en el mercado inmobiliario: se firmó una sola escritura en abril en la provincia de Buenos Aires. Diario Ámbito Financiero. https:/www.ambito.com/ economia/escrituras/paralisis-el-mercado-inmobiliario-se-firmo-una-sola-escritura-abril-laprovincia-buenos-aires-n5105988

FXTOP (s.f.). Cálculo de la inflación y de la evolución de los precios entre dos fechas. Consultado el 27 de agosto de 2020. http://fxtop.com/es/calculadora-de-inflacion.php

Gascón, J. y Cañada, E. (eds.) (2016). Turismo residencial y gentrificación rural. http://www.pasosonline. org/Publicados/pasosoedita/PSEdita_16_Definitivo_e-book.pdf

Harvey, D. (1988). La condición de la Posmodernidad. Amorrortou.

Harvey, D. (2004). El nuevo imperialismo. Akal.

Instituto Nacional de Estadísticas (2018). Síntesis de resultados. Censo 2017. INE.

Jaramillo, S. (2003). Los fundamentos económicos de la participación en plusvalías [documento inédito]. Lincoln Institute of Land Policy - Universidad de los Andes.

Marx, K. (2004). El capital. Crítica de la Economía Política. Tomo III. Volumen 8. Sección Sexta. Transformación de la plusganancias en renta de la tierra (791 1034). Siglo XXI (original publicado en 1894).

Mendoza, F. (2016). La gentrificación en los estudios urbanos: una exploración sobre la producción académica de las ciudades. Cadernos Metrópole, 18 (37), 697-719. https://doi.org/10.1590/22369996.2016-3704

Minaglia, N. y Bages, C. (2020). Mapeo de la Quebrada de Humahuaca. Precios inmobiliarios Imapeo inédito]. Tilcara.

Ministerio de Desarrollo Territorial y Hábitat (2020). Programa de Crédito Argentino del Bicentenario. https://www.argentina.gob.ar/habitat/procrear

Ministerio del Interior, Obras Públicas y Vivienda de Nación (2016). Programa Hábitat. Lineamientos para la Localidad de Tilcara. MOPyV.

Ministerio de Vivienda, Ordenamiento Territorial y Medio Ambiente (2020). Vivienda. República Oriental del Uruguay. https://www.gub.uy/vivienda

Ministerio de Vivienda y Urbanismo (2020). Beneficios Vivienda. Gobierno de Chile. https://www. minvu.cl/beneficios/vivienda/

Municipalidad de Tilcara (2018). Datos de actividades económicas del Municipio de Tilcara linforme no publicado]. Jefatura de Gabinete.

Navegación Aérea Argentina (2018). Informe Mensual Diciembre. Departamento de Estadística. Empresa Argentina de Navegación Aérea (EANA). Ministerio de Transporte. https://www. eana.com.ar/sites/default/files/2019-01/Informe\%20Mensual\%20201812_1.pdf 
Ochoa, P. (2017). Arquitectura para la materialización del poder. Aportes a partir del estudio de nuevos sitios detectados en la Quebrada de Sixilera (Quebrada de Humahuaca, Argentina). Mundo de Antes, 11, 171-194. http://mundodeantes.org.ar/aheadofprint/04-Ochoa.pdf

Ortiz Flores, E. (2012). Producción Social de la Vivienda y el Hábitat. Bases Conceptuales y Correlación con los Procesos Habitacionales. https://hic-al.org/2018/12/28/produccion-social-de-la-vivienda-yel-habitat-bases-conceptuales-y-correlacion-con-los-procesos-habitacionales/

Parias Durán, A. (2010). Reseña de: Hacia una Teoría de la Renta del Suelo Urbano. Samuel Jaramillo González. Territorios, 22, 151-161. https://revistas.urosario.edu.co/index.php/territorios/ article/view/1388/1305

Piketty, T. (2014). El capital en el siglo XXI. Fondo de Cultura Económica.

Schvarzer, J. y Tavonanska, A. (2008). Modelos macroeconómicos en la Argentina: del «stop and go» al «go and crush». CESPA, Documento de Trabajo n 15. FCE - UBA.

Secretaría de Turismo de Jujuy (2017). Mapas de la Provincia de Jujuy. Gobierno de la Provincia de Jujuy.

Ricardo, D. (2004). Principios de Economía Política y Tributación. Fondo de Cultura Económica (original publicado en 1817).

Tommei, C. (2010). Transformaciones del hábitat. Purmamarca después de la apertura del Paso de Jama y de la declaratoria Unesco. Borradores IAA, 1, 2-17. http://www.iaa.fadu.uba.ar/ publicaciones/borradores/Borrador_IAA_01.pdf

Tommei, C. (2017). De ciudad huerta a pueblo boutique: territorio, patrimonio y turismo en Purmamarca, 19912014. [Tesis de Doctorado, Universidad de Buenos Aires, Serie Tesis del IAA. FADU - UBA] 